\title{
Dystonia 12
}

National Cancer Institute

\section{Source}

National Cancer Institute. Dystonia 12. NCI Thesaurus. Code C157577.

An autosomal dominant condition caused by mutation(s) in the ATP1A3 gene, encoding sodium/potassium-transporting ATPase subunit alpha-3. It is characterized by abrupt onset of dystonia and parkinsonism in young adulthood, often triggered by physical or psychological stress. 